POLLUTANTS

BENZENE

ADSORBENT

SEPARATION
EXPOSURE

XYLENE

TENAX GC

ARTIFACTS

Open access manuscript version of

Intern. J. Environ. Anal. Chem. 11 (1982) 211-219

Link to publisher

\title{
Trace analysis of hydrocarbons in air using standard gas chromatographic and personal sampling equipment
}

Mary Mattsson and Göran Petersson

Applications in addition to several studies reported in Swedish include industrial hydrocarbon emissions and exposure to urban hydrocarbons as well as challenging reactive terpene hydrocarbons 
TRACE ANALYSIS OF HYDROCARBONS IN AIR USING STANDARD GAS CHROMATOGRAPHIC

AND PERSONAL SAMPLING EQUIPMENT

Mary Mattsson and Göran Petersson*

Engineering Chemistry and Environment

Cha7mers University of Technology

41296 Göteborg, Sweden 
ABSTRACT

Unmodified standard gas chromatographs are reported to be usefuT for the determination of a large number of ambient hydrocarbons. Packing of standard injector glass liners with an adsorbent permits thermal desorption in the injector on to the chromatographic column. Coupling to a personal sampling pump permits exposure-related sampling. The potential of the technique is illustrated by applications with the Tenax GC adsorbent. Precautions required to avoid artifacts when working in the subnanogram range are described. 
The wide variety of organic compounds in air is of great interest in an environmental context. Rapidly increasing analytical efforts have been devoted to this problem during the last decade. Reviews of analysis of hydrocarbons (1) and a broader range of organics $(2,3)$ in ambient air have been published. Sampling by adsorption, followed by thermal desorption combined with capillary gas chromatography can afford the high analytical resolution and sensitivity required. Comprehensive studies, based on the useful organic polymer Tenax GC (e. $\underline{\text { g. }}$ 4-6) as well as other adsorbents (e.g. 7-9), have been published. So far, most applications have been on stationary sampling. Increased interest in human doses (10) is likely to produce a future trend towards flexible methods permitting exposure-related sampling as we 17.

Most published studies have involved much specialized and/or expensive equipment. Examples are cryogenic sampling, field stations, desorption ovens, modified GC injectors, cold traps or precolumns before the GC column, mass spectrometers and data treatment systems. This may well have discouraged the gas chromatographer without special funds and technical assistance from trying trace analysis of organic air pollutants. The purpose of the present work is to demonstrate the potential of standard GC equipment for this analytical problem. The purpose is also to demonstrate the advantages for exposurerelated studies afforded by a combination with inexpensive.personal monitoring pumps for sampling. 
EXPERIMENTAL SECTION

General approach. The injectors of most standard gas chromatographs are equipped with glass liners to provide an inert space for evaporation of injected liquid samples. These liners are devised so that they can very easily be removed (for cleaning) and inserted again. A basic idea of the approach described is the use of such glass liners as adsorbent tubes.

The glass liner is filled with an appropriate adsorbent which is kept in place by plugs of glass wool or other inert material. The adsorbent is conditioned by placing the liner in the injector and passing carrier gas through at a proper temperature which is set on the gas chromatograph. During transport and storage, the adsorbent tubes are enclosed in glass tubes with stoppers to prevent undue adsorption. On taking a sample, the adsorbent tube is coupled to a personal sampling pump. The model chosen should be easy to carry anywhere and should permit accurate determination of the volume of air.

Ana Tysis by thermal desorption and gas chromatograpy is greatly facilitated by this method of sampling. The proper desorption temperature is preset on the gas chromatograph. The glass liner with adsorbent is placed in the injector with the air inlet end towards the column, and the carrier gas desorbs organic compounds on passing through the liner into the column. The column is kept cool when the adsorbent tube is inserted. This results in retention of desorbed compounds in the injector end of the column. Analysis is then performed by linear temperature programming. 
Specific data. The analytical results reported were obtained on a Carlo Erba 2920 gas chromatograph. The chromatographic column (RSL, Belgium) was a $50 \mathrm{~m} \times 0.25 \mathrm{~mm}$ i.d. glass capillary coated with 0V-101 (high loading) as the stationary phase. The straightened ends were deactivated with a $1 \%$ solution of Carbowax. 1000 before installing the column.

Original glass liners, $80 \times 2.2 \mathrm{~mm}$ i.d., were filled with $0.1-0.2 \mathrm{ml}$ of 60-80 mesh Tenax GC between plugs of silanized glass wool. Initial conditioning was made overnight on the second injector of the instrument at $250^{\circ} \mathrm{C}$ and $20-40 \mathrm{mi} / \mathrm{min}$ of helium. The personal monitoring pumps used, MDA Accuhaler 808, work with constant strike volume and strike counting. The flow resistance of the adsorbent tubes 7 imited the flow of air to about $10 \mathrm{ml} / \mathrm{min}$.

The injector temperature during desorption was set to $200^{\circ} \mathrm{C}$. The column oven was cooled to below $0^{\circ} \mathrm{C}$ before desorption, by blowing $\mathrm{CO}_{2}$ into it from a conventional cylinder. The flow of the carrier gas, helium, through injector and column was $2-3 \mathrm{ml} / \mathrm{min}$. The carrier gas valve was shut during insertion of the adsorbent tube. The opening of the valve marked the start of the analysis which was performed by a $2^{\circ} \mathrm{C} / \mathrm{min}$ programmed increase of temperature from $0^{\circ} \mathrm{C}$. After completing the analysis, the adsorbent tube was ready for conditioning (before taking another sample). This was done at $200^{\circ}$ for 5-15 min by opening the split valve to provide a conditioning flow of $20-40 \mathrm{ml} / \mathrm{min}$.

On the detector side, the column ended very near to the flame of the standard flame ionization detector which was kept at $225^{\circ} \mathrm{C}$. A HewlettPackard 3380A integrator was used for recording the chromatogram, for giving 
retention times, and for automatic integration. It was normally operated on the Towest attenuation. A common response factor was used for the hydrocarbons on calculating concentrations. This factor was determined by analysis of diluted solutions so as to fit benzene and other hydrocarbons with a similar high response. The sum of other analytical errors was estimated to be within $\pm 20 \%$ of the amounts determined except when these were very sma 11.

U7tra-trace analysis and artifacts. The adsorbed amounts of individual hydrocarbons were normally in the range 0.1-100 $\mathrm{ng}$. The minimum detectable amount was less than $0.05 \mathrm{ng}$. Contaminations and artifacts caused many problems before experience was gained on work with these small amounts of substances. Particularly on analysis in the subnanogram range, certain precautions were found to be more or less necessary.

The major problem of preventing adsorption during transport and storage was dealt with in two ways. One approach was to keep solvents, vapours and other sources of contamination away from the room used for analysis and storage. The second and basic approach was to enclose the adsorbent tubes in glass-stoppered glass tubes with just the dimensions needed. These glass tubes were in turn kept in brown glass-stoppered glass bottles together with a couple of small charcoal tubes. In addition, delays between conditioning, sampling and analysis were avoided. The critical transfer of adsorbent tube between injector and glass tube was made quickly in reasonably clean laboratory air. Analysis of blanks proved these precautions to prevent efficiently extra contributions larger than $0.1 \mathrm{ng}$ to individual hydrocarbons. 
The critical coupling of the adsorbent tube to the pump had to be made leak-tight without transfer of disturbing contaminations to the adsorbent tube. Direct coupling to properly cleaned and conditioned latex tubing was found to be satisfactory if analytical demands were not too high. With the Carlo-Erba glass liners, the best joint was found to be an $1 / 4^{\prime \prime}$ stainless steel Swagelok fitting with a teflon ferrule for tightening and a teflon ring inside the fitting to protect the edge of the glass liner. The fitting was stored in a glass bottle together with standard charcoal tubes and was connected to the pump on sampling by narrow-bore tubing (tefion, Tatex) of the length required. No artifacts due to this type of coupling were detected.

Among specific artifacts, several straight-chain aldehydes, particularly the $C_{9}$ and $C_{10}$ species, were difficult to eliminate completely. They appeared in larger amounts on contamination with certain fats and detergents and are likely to be formed by oxidation of olefinic and other linkages, especially in the injector at high temperature. Measures to reduce these artifacts to the subnanogram level involved treatment of glass liners in sulphuric acid with dichromate, initial washing in methanol of teflon details and other equipment getting in contact with the adsorbent tubes, avoiding contact between skin and adsorbent tubes, avoiding fats, oi 15 , soaps and organic detergents at the analytical work-place, and decreasing air leaks into the carrier gas and the injector. 
The use of a silicon membrane in the injector cap to prevent carrier gas leakage gave rise to siloxane artifacts. These were virtually eliminated by using teflon-coated membranes covered by additional teflon discs. The membrane purge flow was not critica1. The absence of disturbing artifacts from the chromatographic system was easily checked by blank runs.

The overal1 performance of the Tenax GC adsorbent was improved by soxhlet extraction in methanol for several hours. The major interfering artifacts formed from the adsorbent itself were found to be benzaldehyde and acetophenone. The resulting broad peaks could usually be reduced in size to insignificance by protecting the adsorption tube from light during sampling, transport, and storage. Trace decomposition of the adsorbent is probably caused by reactive oxidants in the air. A method to prevent such reactions is the introduction of a reducing agent such as thiosulphate at the front end of the adsorption tube (11). Sampling of severely contaminated air introduces metals, nitric acid (from nitrogen oxides), and other catalytically active components which were found to cause artifacts such as aldehydes on continued use. Therefore, the reservation of special adsorbent tubes for comparatively uncontaminated air reduced artifact problems considerably.

The recovery of trace amounts of hydrocarbons was studied by a comparison of the results obtained for sma 11 and large volumes of samples taken simultaneously at the same place. Recovery and possible artifact formation of hydrocarbons were also studied for samples taken simultaneously on Tenax GC and Carbopack B (cf. 7). When observing the precautions discussed, no significant losses or artifact contributions were observed for the aliphatic and aromatic hydrocarbons studied. 
RESULTS AND DISCUSSION

Applications. The chromatogram reproduced in Figure 1 illustrates the sensitivity and the resolution of the method. The selected results given in Table I demonstrate the versatility for different applications. The examples were chosen among many samples of each category so as to reflect typical concentration levels.

The aromatic hydrocarbons selected for Table I, as well as all other $C_{9}-C_{10}$ a 7 kylbenzenes, normally originate almost exclusively from gasoline and car exhaust in urban environments. The same is true of the $C_{7}$ alkanes chosen to represent $C_{4}-C_{8}$-alkanes, methylalkanes and naphtenes, although other sources such as light petroleum solvents exist. The $\mathrm{C}_{10}$ alkanes were chosen to represent unbranched and the multitude of branched $C_{9}-C_{14}$ alkanes, which originate mainty from diesel oil and diesel exhaust.

The regional overnight sample was takèn under winter conditions without near-by upwind traffic. The recorded concentrations are similar to those obtained in a German study of regional background pollutants (12). For the next five samples, hydrocarbons from automobiles predominate. The almost constant ratios between the concentrations of the aromatic hydrocarbons are typical for this source. The indoor concentrations near to traffic are often much higher than those given in the example. The data given for walking, cycling and car-driving represent typical average levels of exposure. As a general rule, concentrations depend primarily on the distance to cars and car traffic. The guard's position east of King's castle in Stockholm is near to a street with considerable diesel traffic. This is reflected in high concentrations of the $\mathrm{C}_{10}$ a 7 kanes. The last example is taken from a recent study of immissions 


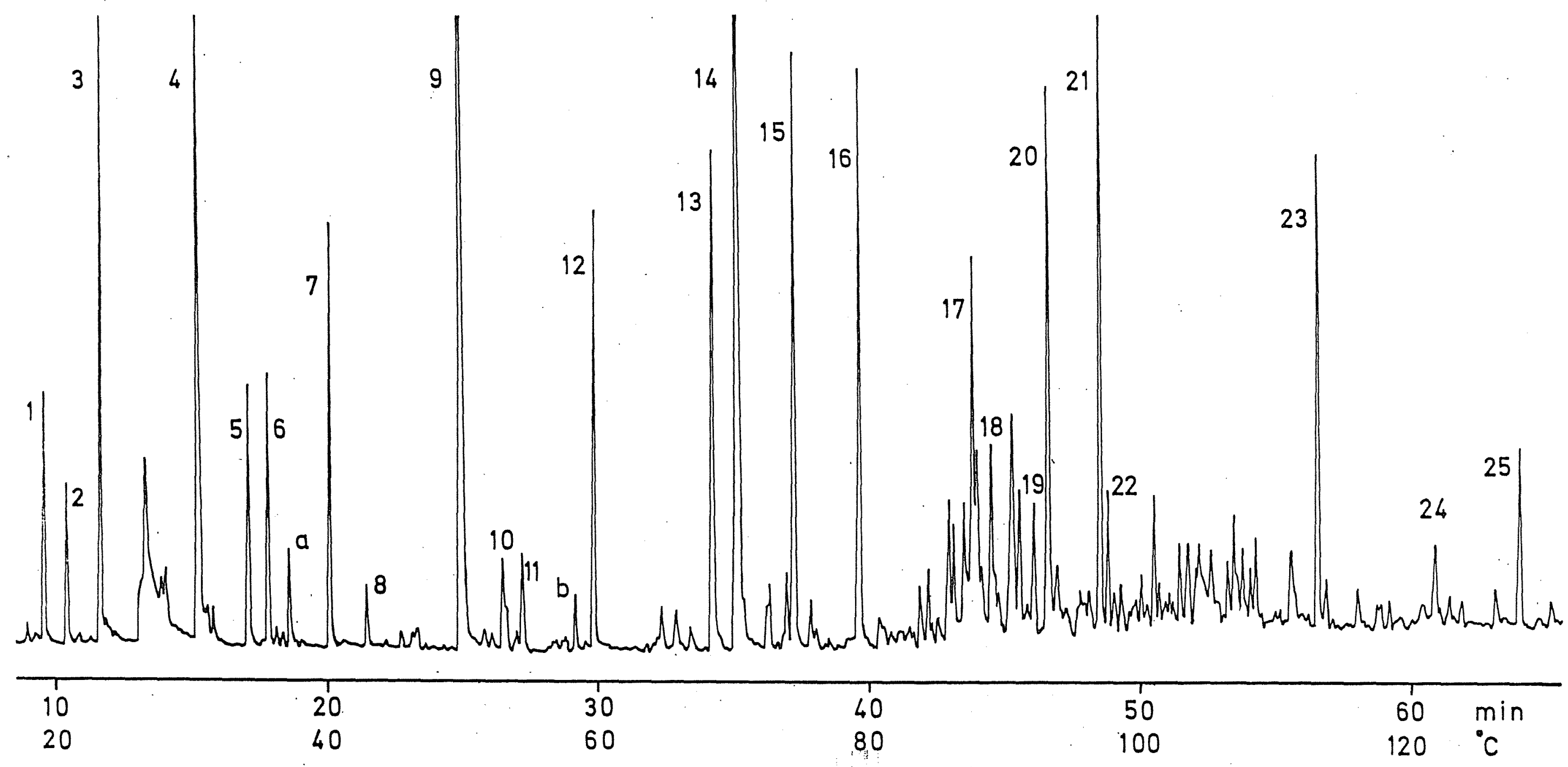

Figure 1. Analysis of hydrocarbons in regional air in Göteborg, Sweden. Peak identities supplementing the data given in Table I: (1), 2-methy 1-pentane; (2), 3-methylpentane; (3), n-hexane; (5), 2-methylhexane; (10), 2-methylheptane; (11), 3-methylheptane; (12), n-octane;
(16): n-nonane; (17), 1-ethy 1-3-methylbenzene; (18), 1,3,5-trimethy 1-

-benzene; (22), 1,2,3-trimethylbenzene; (23), n-undecane; (25), n-dodecane; (a), trichloroethylene, $0.47 \mathrm{\mu g} / \mathrm{m}^{3}$ (rel. response 0.20$)$; (b), tetrachloro-ethy.lene, $0.31 \mu \mathrm{g} / \mathrm{m}^{3}$ (rel. response 0.16 ). 
TABLE I

Representative hydrocarbon concentrations $\left(\mu \mathrm{g} / \mathrm{m}^{3}\right)$ in air samples corresponding to different analytical applications

\begin{tabular}{|c|c|c|c|c|c|c|c|}
\hline & $\begin{array}{c}\text { regional air } \\
570 \mathrm{~min}, 7600 \mathrm{ml}\end{array}$ & $\begin{array}{c}\text { indoor air } \\
30 \mathrm{~min}, 410 \mathrm{ml}\end{array}$ & $\begin{array}{c}\text { pedestrian }^{\mathrm{d}} \\
24 \mathrm{~min}, 258 \mathrm{ml}\end{array}$ & $\begin{array}{c}\text { cyclist }^{\mathrm{c}} \\
15 \mathrm{~min}, 152 \mathrm{ml}\end{array}$ & $\begin{array}{c}\text { motorist }^{\mathrm{c}} \\
9 \mathrm{~min}, 93 \mathrm{ml}\end{array}$ & $\begin{array}{l}\text { Royal Castle } \\
20 \mathrm{~min}, 223 \mathrm{ml}\end{array}$ & $\begin{array}{l}\text { Volvo plant } \\
30 \mathrm{~min}, 286 \mathrm{ml}\end{array}$ \\
\hline benzene $(4)^{\mathrm{a}}$ & 1.30 & 4.0 & 14 & 34 & 56 & 13 & 3.1 \\
\hline \multicolumn{8}{|l|}{ alkylbenzenes } \\
\hline toluene (9) & 2.53 & 12.4 & 37 & 84 & 142 & 33 & 12 \\
\hline ethylbenzene (13) & 0.54 & 2.7 & 7.4 & 15 & 27 & 8.0 & 28 \\
\hline xylene $(m, p)(14)$ & 1.72 & 9.3 & 27 & 56 & 97 & 29 & 85 \\
\hline xylene $(o)(15)$ & 0.61 & 3.4 & 10 & 21 & 35 & 12 & 12 \\
\hline 1,2,4-trimethylbenzene (20) & 0.55 & 3.6 & 9 & 20 & 31 & 16 & 20 \\
\hline naphtalene (24) & 0.07 & 0.6 & 0.7 & 1.8 & 3.2 & 1.3 & 1.4 \\
\hline \multicolumn{8}{|l|}{ alkanes } \\
\hline$n$-heptane (7) & 0.37 & 0.9 & 3.0 & 8.0 & 8.7 & 4.0 & 1.2 \\
\hline 3-methylhexane (6) & 0.24 & 1.1 & 3.1 & 10 & 11 & 3.2 & 0.8 \\
\hline methylcyclohexane (8) & 0.06 & 0.1 & 0.5 & 1.1 & 0.8 & 0.6 & 0.5 \\
\hline$n$-decane (21) & 0.78 & 3 & 2.7 & 2.4 & 5.7 & 16 & 13 \\
\hline 3-methylnonane (19) & 0.12 & 0.3 & 0.4 & 0.5 & 0.7 & 2.7 & 1.9 \\
\hline
\end{tabular}

"Numbers in parenthesis refer to Figure 1.

${ }^{b} B a l c o n y$ on the $7 \mathrm{th}$ floor, $2-3 \mathrm{~km}$ downwind and south of the city centre of Göteborg, $2 / 11-12 / 81,21.30-07.00,-5^{\circ} \mathrm{C}$ to $-10^{\circ} \mathrm{C}$

'Student's dining-hall, Chalmers University, 50-100 m Irom traflic, 10/14/80, 11.00.

${ }^{\rfloor}$Mean exposure on walking along the Avenue of Göteborg, 2/05/80, 11.00.

'Mean exposure on cycling and car-driving, the same distance and streets, 9/22/80, 13.30.

'Stockholm, guard's position near throughtraffic, 3/17/80, 18.00 .

${ }^{8}$ Downwind $(1 \mathrm{~km})$ from a major car assembly plant in western Göteborg, 1/14/81, 15.00 . 
from automotive assembly plants (13) with the analytical technique described. As expected, the hydrocarbon pattern is quite different from that of the traffic immissions. In addition to emission rates and the distance from the sources, weather parameters such as wind, precipitation and inversions influenced observed concentrations significantly.

The examples given, e.g. for cycling, walking and car-driving, illustrate the potential of the method for exposure-related studies. Dose relationships are obtained by a combination with exposure time and 7 ung ventilation studies. Of great value in ecotoxicological studies is also the high sensitivity which permits comparisons with background leve1s. A further advantage is the simultaneous determination of a large number of compounds. As illustrated by the examples, this often permits the identification of the sources of pollution.

Analytical versatility. As illustrated by Figure 1, the mixture of analyzed pollutants is complex and would appear to require coupling with mass spectrometry for identification. The compounds are the same as those of the few major sources of pollutants however, and a facile method of identification was found to be comparisons with the composition of gasoline and other sources of emissions. A combination with cochromatography, comparisons with literature data, and theoretical retention considerations provides very reliable identifications. In addition to those numbered in Figure 1, 20-30 hydrocarbons were identified. They were mainly alkylbenzenes and branched alkanes. The prominent as well as the minor pollutants tend to be the same in most urban environments.

The break-through volumes on the Tenax GC adsorbent tube (14) limit the range of hydrocarbons which can be analyzed quantitatively. In spite of an unusual1y smal1 amount of adsorbent, quantitative results 
were obtained with benzene and all later-eluting hydrocarbons in the present study. The range increases somewhat with decreased sampling volume and temperature and vice versa. On the other hand, increased sampling volume permits analysis of lower concentrations.

The precautions on uitra-trace analysis described in the experimental section may appear troublesome but are in practice easy to observe for the careful analyst. With regard to possible leakages and contaminations, duplicate samples are valuable to assure particularly reliable results. It is also an advantage if equipment used for ultra-trace analysis can be reserved for the purpose. In return, year-long high-quality performance of columns and adsorbent tubes can be obtained. The analysis shown in Figure 1 was made after almost one year's use of the same capillary column.

When demands for resolution and sensitivity are lower, the analytical procedure can be rationalized very much. Samples from exposure studies in traffic environments were routinely analyzed on a Perkin-Elmer 900 instrument. The use of a phenyl silicone column (SCOT, OV-17) permitted analyses of the major aromatic hydrocarbons of interest in less than 30 minutes. This instrument had an injector without splitting device and was intermittently used for very different analytical problems and with different columns. Hydrocarbons in amounts less than $10 \mathrm{ng}$ could be analyzed with a minimum of precautions. The possibility of adapting the analytical procedure to the problem and the equipment at hand is a major advantage of the analytical technique described. 


\section{LITERATURE CITED}

(1) Leinster, P.; Perry, R.; Yong, R.J. Talanta 1977, 24, 205.

(2) Lamb, S.I.; Petrowski, C.; Kaplan, I.R.; Simoneit, B.R.T. JAPCA $1980,30,1098$.

(3) Fox, D.L.; Jeffries, H.E. Ana1. Chem. 1981, 53, 1R.

(4) Versino, B.; Knöppe1, H.; De Groot, M.; Pei1, A.; Poelman, J.; Schauenburg, H.; Vissers, H.; Geiss, F. J. Chromatogr. 1976, $122,373$.

(5) Pellizzari, E.D.; Bunch, J.E.; Berkley, R.E.; McRae, J. Ana 1. Chem. 1976;" 48, 803.

(6) Holzer, G.; Shanfield, H.; Zlatkis, A.; Bertsch, W.; Juarez, P.; Mayfield, H.; Liebich, H.M. J. Chromatogr. 1977, 142, 755.

(7) Ciccioli, P.; Bertoni, G.; Brancaleoni, E.; Fratarcangeli, R.; Bruner, F. J. Chromatogr. 1976, 126, 757.

(8) Louw, C.W.; Richards, J.F.; Faure, P.K. Atmospheric Environment $1977,11,703$.

(9) Ioffe, B.V.; Isidorov, V.A.; Zenkevich, I.G. Environ. Sci. Technol. 1979, 13, 864.

(10) Singh, H.B.; Salas, L.J.; Smith, A.J.; Shigeishi, H. Atmospheric Environment 1981, 15, 601.

(11) Bunch, J.E.; Pellizzari, E.D.; J. Chromatogr. 1979, 186, 811.

(12) Bergert, K.-H.; Betz, V. Chromatographia 1974, $\underline{7}, 681$.

(13) Petersson, G. Environ. Pollut. Ser. B, in press.

(14) Brown, R.H.; Purne11, C.J. J. Chromatogr. 1979, 178, 79. 